Shao-Qiang Hu* and Shi-Hui Li

\title{
Crystal structure of poly[bis $\left\{\mu_{2}-5\right.$-carboxy-4'- methyl-[1,1'-biphenyl]-3-carboxylato- $\left.\mathrm{K}^{2} 0: 0^{\prime}\right\}-\left\{\mu_{2}-\right.$ 4,4'-bipyridine- $\left.\mathrm{K}^{2} \mathrm{~N}: \mathrm{N}^{\prime}\right\}$ ] cobalt(II), $\mathrm{C}_{40} \mathrm{H}_{30} \mathrm{~N}_{2} \mathrm{O}_{8} \mathrm{Co}$
}

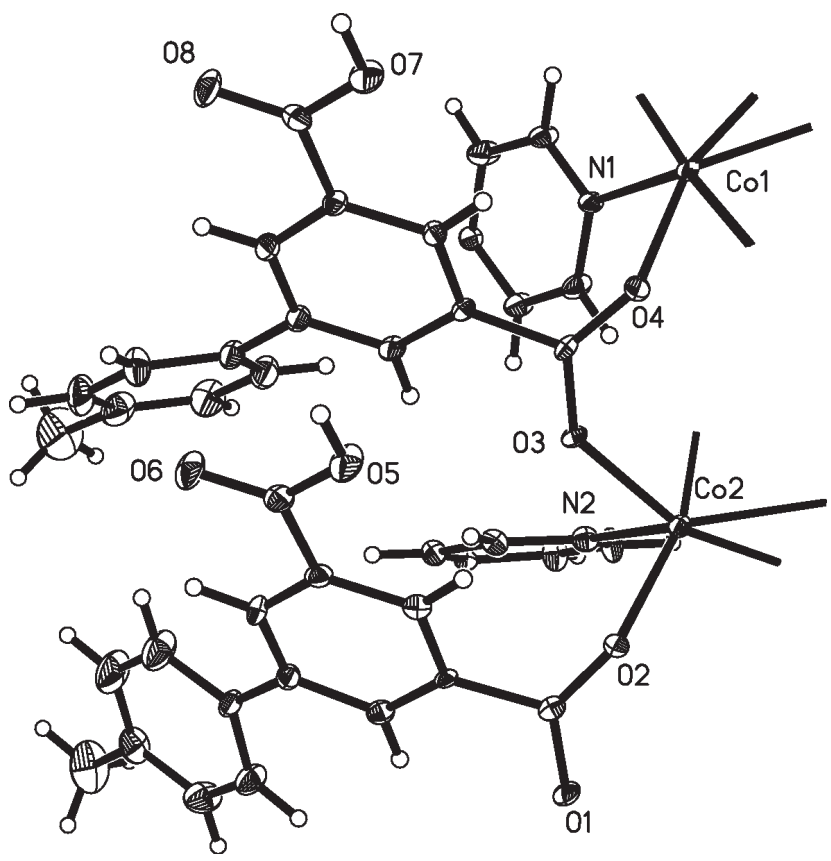

https://doi.org/10.1515/ncrs-2020-0205

Received April 25, 2020; accepted June 10, 2020; available online June 20, 2020

\section{Abstract}

$\mathrm{C}_{40} \mathrm{H}_{30} \mathrm{~N}_{2} \mathrm{O}_{8} \mathrm{Co}, \quad$ triclinic, $P \overline{1} \quad$ (no. 2), $\quad a=9.8766(6) \AA$, $b=11.5473(8) \AA, \quad c=14.2194(9) \AA, \quad \alpha=84.534(5)^{\circ}$, $\beta=85.582(5)^{\circ}, \quad \gamma=79.413(5)^{\circ}, \quad V=1583.90(17) \AA^{3}, \quad Z=2$, $R_{\mathrm{gt}}(F)=0.0650, w R_{\text {ref }}\left(F^{2}\right)=0.1109, T=293(2) \mathrm{K}$.

\section{CCDC no.: 2009051}

A part of the polymeric title structure is shown in the figure. Table 1 contains crystallographic data and Table 2 contains the list of the atoms including atomic coordinates and displacement parameters.

*Corresponding author: Shao-Qiang Hu, College of Chemistry and Chemical Engineering, Luoyang Normal University, Luoyang, Henan 471934, P.R. China, e-mail: husq2020@126.com. https://orcid.org/ 0000-0003-0189-4299

Shi-Hui Li: College of Chemistry and Chemical Engineering, Luoyang Normal University, Luoyang, Henan 471934, P.R. China
Table 1: Data collection and handling.

\begin{tabular}{ll}
\hline Crystal: & Red block \\
Size: & $0.42 \times 0.38 \times 0.31 \mathrm{~mm}$ \\
Wavelength: & Mo $K \alpha$ radiation $(0.71073 \AA)$ \\
$\mu:$ & $0.61 \mathrm{~mm}^{-1}$ \\
Diffractometer, scan mode: & SuperNova, $\omega$ \\
$\theta_{\text {max }}$, completeness: & $25.5^{\circ}, 99 \%$ \\
$N(h k l)_{\text {measured }}, N(h k l)_{\text {unique }}, R_{\text {int }}:$ & $12944,5740,0.053$ \\
Criterion for $I_{\text {obs }}, N(h k l)_{\mathrm{gt}}:$ & $I_{\text {obs }}>2 \sigma\left(I_{\text {obs }}\right), 3354$ \\
$N(\text { param })_{\text {refined }}:$ & 467 \\
Programs: & CrysAlis ${ }^{\text {PRO }}[1]$, SHELX $[2,3]$ \\
\hline
\end{tabular}

Table 2: Fractional atomic coordinates and isotropic or equivalent isotropic displacement parameters $\left(\AA^{2}\right)$.

\begin{tabular}{lrrrr}
\hline Atom & $\boldsymbol{x}$ & $\boldsymbol{y}$ & $\boldsymbol{z}$ & $\boldsymbol{U}_{\text {iso }}{ }^{*} \boldsymbol{U}_{\text {eq }}$ \\
\hline C01 & 1.0000 & 1.0000 & 0.5000 & $0.0170(2)$ \\
Co2 & 0.5000 & 1.0000 & 0.5000 & $0.0179(2)$ \\
N1 & $0.9991(3)$ & $0.8088(3)$ & $0.5057(2)$ & $0.0204(8)$ \\
N2 & $0.5035(3)$ & $0.8079(3)$ & $0.5073(2)$ & $0.0229(9)$ \\
O1 & $0.1449(3)$ & $0.9777(2)$ & $0.38516(18)$ & $0.0236(7)$ \\
O2 & $0.3449(2)$ & $1.0372(2)$ & $0.40291(18)$ & $0.0219(7)$ \\
O3 & $0.6453(2)$ & $0.9747(2)$ & $0.38784(18)$ & $0.0225(7)$ \\
O4 & $0.8338(2)$ & $1.0471(2)$ & $0.41238(18)$ & $0.0222(7)$ \\
O5 & $0.6397(3)$ & $1.0376(3)$ & $0.0993(2)$ & $0.0373(8)$ \\
H5 & 0.7050 & 1.0525 & 0.0639 & $0.056^{*}$ \\
O6 & $0.6645(3)$ & $0.8808(3)$ & $0.0152(2)$ & $0.0365(8)$ \\
O7 & $1.1321(3)$ & $1.0598(3)$ & $0.1028(2)$ & $0.0365(8)$ \\
H7 & 1.1959 & 1.0771 & 0.0671 & $0.055^{*}$ \\
O8 & $1.1632(3)$ & $0.9027(3)$ & $0.0188(2)$ & $0.0368(8)$ \\
C1 & $0.2693(4)$ & $0.9838(3)$ & $0.3620(3)$ & $0.0182(10)$ \\
C2 & $0.3324(4)$ & $0.9208(4)$ & $0.2765(3)$ & $0.0167(10)$ \\
C3 & $0.2951(4)$ & $0.8143(4)$ & $0.2611(3)$ & $0.0227(11)$ \\
H3 & 0.2213 & 0.7904 & 0.2975 & $0.027^{*}$ \\
C4 & $0.3642(4)$ & $0.7418(4)$ & $0.1931(3)$ & $0.0217(10)$ \\
C5 & $0.4656(4)$ & $0.7870(4)$ & $0.1344(3)$ & $0.0269(11)$ \\
H5A & 0.5107 & 0.7436 & 0.0858 & $0.032^{*}$ \\
C6 & $0.5002(4)$ & $0.8946(4)$ & $0.1469(3)$ & $0.0218(10)$ \\
C7 & $0.4381(4)$ & $0.9603(4)$ & $0.2201(3)$ & $0.0216(10)$ \\
H7A & 0.4669 & 1.0298 & 0.2313 & $0.026^{*}$ \\
C8 & $0.3351(4)$ & $0.6213(4)$ & $0.1876(3)$ & $0.0254(11)$ \\
C9 & $0.2152(4)$ & $0.5881(4)$ & $0.2286(3)$ & $0.0359(12)$ \\
H9 & 0.1486 & 0.6437 & 0.2573 & $0.043^{*}$ \\
C10 & $0.1925(5)$ & $0.4735(4)$ & $0.2278(4)$ & $0.0458(14)$ \\
H10 & 0.1111 & 0.4538 & 0.2567 & $0.055^{*}$ \\
& & & &
\end{tabular}

ð Open Access. ( 2020 Shao-Qiang Hu et al., published by De Gruyter. (c) BY This work is licensed under the Creative Commons Attribution 4.0 International License. 
Table 2 (continued)

\begin{tabular}{|c|c|c|c|c|}
\hline Atom & $x$ & $y$ & $z$ & $\boldsymbol{U}_{\text {iso }}{ }^{\star} / \boldsymbol{U}_{\text {eq }}$ \\
\hline C11 & $0.2860(5)$ & $0.3883(4)$ & $0.1856(4)$ & $0.0417(14)$ \\
\hline C12 & $0.4055(6)$ & $0.4202(5)$ & $0.1446(4)$ & $0.0608(16)$ \\
\hline $\mathrm{H} 12$ & 0.4718 & 0.3642 & 0.1162 & $0.073^{*}$ \\
\hline C13 & $0.4285(5)$ & $0.5356(4)$ & $0.1453(4)$ & $0.0534(15)$ \\
\hline H13 & 0.5097 & 0.5553 & 0.1160 & $0.064^{\star}$ \\
\hline C14 & $0.6096(4)$ & $0.9373(4)$ & $0.0810(3)$ & $0.0249(11)$ \\
\hline C15 & $0.2576(6)$ & $0.2643(4)$ & $0.1874(4)$ & $0.0741(19)$ \\
\hline $\mathrm{H} 15 \mathrm{~A}$ & 0.3295 & 0.2176 & 0.1507 & $0.111^{\star}$ \\
\hline H15B & 0.1706 & 0.2662 & 0.1610 & $0.111^{\star}$ \\
\hline $\mathrm{H} 15 \mathrm{C}$ & 0.2546 & 0.2299 & 0.2515 & $0.111^{\star}$ \\
\hline C16 & $0.7690(4)$ & $0.9863(3)$ & $0.3695(3)$ & $0.0157(9)$ \\
\hline C17 & $0.8419(4)$ & $0.9229(3)$ & $0.2882(3)$ & $0.0183(10)$ \\
\hline C18 & $0.8104(4)$ & $0.8148(4)$ & $0.2679(3)$ & $0.0231(11)$ \\
\hline $\mathrm{H} 18$ & 0.7443 & 0.7829 & 0.3071 & $0.028^{*}$ \\
\hline C19 & $0.8721(4)$ & $0.7533(4)$ & $0.1932(3)$ & $0.0224(10)$ \\
\hline $\mathrm{C} 20$ & $0.9670(4)$ & $0.8038(4)$ & $0.1325(3)$ & $0.0259(11)$ \\
\hline $\mathrm{H} 20$ & 1.0077 & 0.7656 & 0.0800 & $0.031^{*}$ \\
\hline $\mathrm{C} 21$ & $1.0013(4)$ & $0.9116(4)$ & $0.1501(3)$ & $0.0212(10)$ \\
\hline $\mathrm{C} 22$ & $0.9412(4)$ & $0.9696(3)$ & $0.2278(3)$ & $0.0180(10)$ \\
\hline $\mathrm{H} 22$ & 0.9668 & 1.0400 & 0.2400 & $0.022^{\star}$ \\
\hline $\mathrm{C} 23$ & $0.8442(4)$ & $0.6346(4)$ & $0.1783(3)$ & $0.0268(11)$ \\
\hline C24 & $0.8438(5)$ & $0.5950(4)$ & $0.0899(3)$ & $0.0399(13)$ \\
\hline $\mathrm{H} 24$ & 0.8576 & 0.6457 & 0.0366 & $0.048^{\star}$ \\
\hline $\mathrm{C} 25$ & $0.8235(5)$ & $0.4821(5)$ & $0.0784(4)$ & $0.0539(15)$ \\
\hline $\mathrm{H} 25$ & 0.8213 & 0.4590 & 0.0177 & $0.065^{\star}$ \\
\hline $\mathrm{C} 26$ & $0.8064(5)$ & $0.4028(4)$ & $0.1559(4)$ & $0.0463(14)$ \\
\hline $\mathrm{C} 27$ & $0.8055(5)$ & $0.4412(4)$ & $0.2446(4)$ & $0.0455(14)$ \\
\hline $\mathrm{H} 27$ & 0.7924 & 0.3900 & 0.2977 & $0.055^{\star}$ \\
\hline $\mathrm{C} 28$ & $0.8236(4)$ & $0.5544(4)$ & $0.2559(3)$ & $0.0389(13)$ \\
\hline $\mathrm{H} 28$ & 0.8222 & 0.5782 & 0.3167 & $0.047^{\star}$ \\
\hline $\mathrm{C} 29$ & $0.7896(6)$ & $0.2781(4)$ & $0.1429(4)$ & $0.090(2)$ \\
\hline $\mathrm{H} 29 \mathrm{~A}$ & 0.7522 & 0.2434 & 0.2009 & $0.136^{*}$ \\
\hline $\mathrm{H} 29 \mathrm{~B}$ & 0.8779 & 0.2321 & 0.1259 & $0.136^{*}$ \\
\hline $\mathrm{H} 29 \mathrm{C}$ & 0.7282 & 0.2793 & 0.0935 & $0.136^{*}$ \\
\hline C30 & $1.1067(4)$ & $0.9581(4)$ & $0.0842(3)$ & $0.0237(11)$ \\
\hline C31 & $0.5181(4)$ & $0.7560(3)$ & $0.4264(3)$ & $0.0214(10)$ \\
\hline H31 & 0.5297 & 0.8027 & 0.3704 & $0.026^{\star}$ \\
\hline C32 & $0.5170(4)$ & $0.6374(4)$ & $0.4202(3)$ & $0.0231(10)$ \\
\hline H32 & 0.5273 & 0.6066 & 0.3614 & $0.028^{\star}$ \\
\hline C33 & $0.5004(4)$ & $0.5643(3)$ & $0.5023(3)$ & $0.0174(10)$ \\
\hline C34 & $0.4901(4)$ & $0.6171(4)$ & $0.5869(3)$ & $0.0309(12)$ \\
\hline H34 & 0.4831 & 0.5720 & 0.6443 & $0.037^{\star}$ \\
\hline C35 & $0.4904(4)$ & $0.7371(4)$ & $0.5857(3)$ & $0.0308(12)$ \\
\hline H35 & 0.4810 & 0.7703 & 0.6434 & $0.037^{\star}$ \\
\hline C36 & $0.8840(4)$ & $0.7637(4)$ & $0.5179(3)$ & $0.0285(11)$ \\
\hline H36 & 0.8010 & 0.8153 & 0.5277 & $0.034^{\star}$ \\
\hline C37 & $0.8800(4)$ & $0.6453(4)$ & $0.5170(3)$ & $0.0289(11)$ \\
\hline H37 & 0.7960 & 0.6192 & 0.5267 & $0.035^{\star}$ \\
\hline H39 & 1.2047 & 0.5622 & 0.4784 & $0.040^{*}$ \\
\hline C38 & $1.0001(4)$ & $0.5648(3)$ & $0.5016(3)$ & $0.0211(10)$ \\
\hline C39 & $1.1203(4)$ & $0.6116(4)$ & $0.4892(3)$ & $0.0337(12)$ \\
\hline C40 & $1.1152(4)$ & $0.7312(4)$ & $0.4927(3)$ & $0.0257(11)$ \\
\hline $\mathrm{H} 40$ & 1.1980 & 0.7595 & 0.4855 & $0.031^{*}$ \\
\hline
\end{tabular}

\section{Source of material}

A mixture of $\mathrm{Co}(\mathrm{OAc})_{2} \cdot 6 \mathrm{H}_{2} \mathrm{O}(0.1 \mathrm{mmol}, 29.1 \mathrm{mg}), 4,4^{\prime}$ bipyridine ( $0.1 \mathrm{mmol}, 15.6 \mathrm{mg})$, and 3',5'-dicarboxyl-4-methyl biphenyl $\left(\mathrm{H}_{2} \mathrm{dmb}\right)(0.1 \mathrm{mmol}, 25.6 \mathrm{mg})$, was dissolved in $9 \mathrm{~mL}$ $\mathrm{H}_{2} \mathrm{O}$. The solution was heated in a $23 \mathrm{~mL}$ Teflon-lined autoclave under autogenous pressure at $383 \mathrm{~K}$ for four days. After cooling to room temperature crystals formed.

\section{Experimental details}

Coordinates of hydrogen atoms were positioned using geometrical considerations. Their $U_{\text {iso }}$ values were set to $1.2 U_{\text {eq }}$ of the parent atoms.

\section{Comment}

In the last two decades, a large number of mixed ligands MOFs have been reported. Mixed ligands MOFs can be constructed from metal ions and carboxylic acid and nitrogencontaining ligands $[4,5]$. In most situations, $N$-containing ligands are electrically neutral, while carboxylate ligands are negatively charged. Among organic aromatic multicarboxylates like the $3^{\prime}, 5^{\prime}$-dicarboxyl-4-methyl biphenyl can yield networks and have been widely utilized to construct MOFs [6, 7]. On the other hand, 4,4'-bipyridine serves as bridging ligand to coordinate two metal ions $[8,9]$.

In the title complex, there are two half $\mathrm{Co}(\mathrm{II})$ ions, two monoanionic Hdmb ligands, and two half of the 4,4'bipyridine ligand in the asymmetric unit. The atom Co1 is sixcoordinated with a distorted octahedral geometry by four $\mathrm{O}$ atoms from the Hdmb ligands, and two $\mathrm{N}$ atoms from two 4,4'bipyridine ligands from the axial positions (see the figure). The $\mathrm{Co}-\mathrm{N}$ bond length is 2.204(3) $\AA$; and the $\mathrm{Co}-\mathrm{O}$ ones are in the range of 2.089(3) to 2.098(2) $\AA$. The bond angles of OCo $-\mathrm{O}$ are in the range of $87.13(10)^{\circ}$ to $180^{\circ}$. The $\mathrm{Co} 2$ is sixcoordinated with a distorted octahedral geometry by four $\mathrm{O}$ atoms from the Hdmb ligands, and two $\mathrm{N}$ atoms from two 4,4'bipyridine ligands from the axial positions. The $\mathrm{Co}-\mathrm{N}$ bond length is 2.204(3) $\AA$; and the $\mathrm{Co}-\mathrm{O}$ ones are in the range of $2.066(3)$ to $2.100(2) \AA$. The bond angles of $\mathrm{O}-\mathrm{Co}-\mathrm{O}$ are in the range of $88.94(10)^{\circ}$ to $180^{\circ}$. All geometric parameters are comparable to related ones [10]. Co(II) ions are linked by 4,4'bipyridine ligands and Hdmb ligands to form a 2-D layer. The lengths of bipy and the methy-biphenyl groups are almost the same. In the packing scheme of the title coordination polymers these moieties are arranged in a parallel fashion which is known as dimensional caging [11] in particular bipyridine and its derivatives is a prominent class of compounds to be used for dimensional caging [12]. This arrangement seems to further contribute to the structure formation. 
Acknowledgements: The authors thank the Key Scientific Research Project for Universities of Henan Province (No. 18B150015; No. 20A150028) and Science and Technology Research Project of Henan Province (no. 182102310909) for financial support.

\section{References}

1. Agilent Technologies: CrysAlis ${ }^{\mathrm{PRO}}$ Software system, version 1.171.35.15. Agilent Technologies UK Ltd, Oxford, UK (2011).

2. Sheldrick, G. M.: SHELXT - Integrated space-group and crystalstructure determination. Acta Crystallogr. A71 (2015) 3-8.

3. Sheldrick, G. M.: Crystal structure refinement with SHELXL. Acta Crystallogr. C71 (2015) 3-8.

4. Li, S. H.; Han, M. L.; Liu, G. Z.; Ma, L. F.; Wang, L. Y.: Guest induced single-crystal-to-single-crystal transformations of a new 4-connected 3D cadmium(II) metal-organic framework. RSC Adv. 5 (2015) 17588-17591.

5. Li, S. H.; Zang, J.; Guo, J. B.: Synthesis and crystal structure of a new three-dimensional $\mathrm{Ho}$ (II) coordination polymer based on 5'-(4-carboxyphenyl)-[1,1':3',1'-terphenyl] -4,4'-dicarboxylic acid. Inorg. Nano-Met. Chem. 12 (2017) 1746-1749.

6. Chen, S. J.; Li, S. H.; Wang, W. H.; Long, Y. F.; Zhang, W. I.; Wang, T.; Xu, Y. L.: Crystal structure of poly[aqua- $\mu_{2}-4,4^{\prime}$-bis (pyrid-4-yl)biphenyl- $\left.{ }^{2} N: N^{\prime}\right)-\mu_{4}-4^{\prime}$-methyl-[1,1'-biphenyl]-3, 5-dicarboxylato- $\left.\kappa^{4} O: O^{\prime}: O^{\prime \prime}: O^{\prime \prime \prime}\right)$ manganese(II)]. Z. Kristallogr. NCS 234 (2019) 373-375.

7. Song, W.; Li, S. H.; Xu, X. L.: Crystal structure of 4-(4'(pyridin-4-yl)-[1,1'-biphenyl]-4-yl)pyridin-1-iumcatena-poly [\{5-carboxy-4'-methyl-[1,1'-biphenyl]-3-carboxylato- $\left.\mathrm{K}^{2} \mathrm{O}, \mathrm{O}^{\prime}\right\}$ ( $\mu_{2}-4^{\prime}$-methyl-[1,1'-biphenyl]-3,5-dicarboxylato- $\left.{ }^{4} O, O^{\prime}: O^{\prime \prime}, O^{\prime \prime \prime}\right)$ lead(II)]. Z. Kristallogr. NCS 233 (2018) 51-53.

8. Li, S. H.; Zhao, Y.: Synthesis and crystal structure of a new three-dimensional $\mathrm{Co}$ (II) coordination polymer based on 3,3',4,5'-biphenyl tetracarboxylic acid and 4,4'-bipyridine. Inorg. Nano-Met. Chem. 47 (2017) 256-259.

9. Yao, L. P.; Zhao, Y.: Crystal structure of 4,4'-bipyridin-1-ium 3,3',5'-tricarboxy-[1,10-biphenyl]-2-carboxylate. Z. Kristallogr. NCS 233 (2018) 51-53.

10. Zhang, M.-N.; Zheng, X.-L.; Qu, X.-L.; Li, X.; Gao, Y.; Xuebao, W. H.: Synthesis, crystal structures and fluorescence sensing for $\mathrm{Fe}^{3+}$ of transition metal complexes with 3,4,5,6tetrafluorophtalic acid and $\mathrm{N}$-donor Ligands. Chin. J. Inorg. Chem. 33 (2017) 1172-1180.

11. Svensson, P. H.; Gorlov, M.; Kloo, L.: Dimensional caging of polyiodides. Inorg. Chem. 47 (2008) 11464-11466.

12. Reiss, G. J.; van Megen, M.: Two new polyiodides in the 4,4'bipyridinium diiodide/iodine system. Z. Naturforsch. B 67 (2012) 5-10. 